
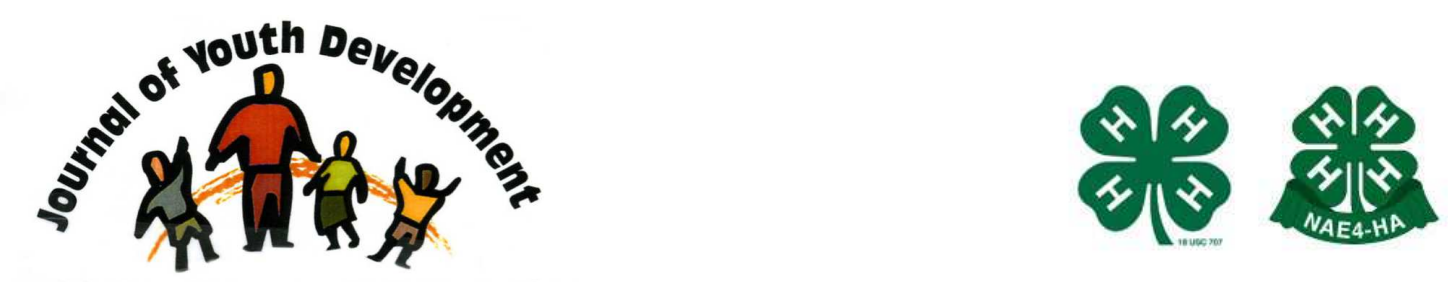

Bridging Research \& Practice

\title{
Time Spent in Sports and Adolescent Problem Behaviors: A Longitudinal Analysis of Directions of Association
}

\author{
Adam C. Sheppard \\ Department of Education \\ University of California, Irvine \\ Irvine, CA \\ adam.sheppard@uci.edu \\ Joseph L. Mahoney \\ Department of Education \\ University of California, Irvine \\ Irvine, CA \\ jlmahone@uci.edu
}




\title{
JOURNAL OF YOUTH DEVELOPMENT \\ bridging research and practice

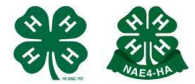

Volume 7, Number 3, Fall 2012

Article 120703RS001

\section{Time Spent in Sports and Adolescent Problem Behaviors: A Longitudinal Analysis of Directions of Association}

\author{
Adam C. Sheppard and Joseph L. Mahoney \\ University of California, Irving
}

\begin{abstract}
This longitudinal study analyzed the direction of the association between sports participation and problem behavior. Participants were a nationally representative sample of 1,692 adolescents (ages 11-19). Results showed that, beyond baseline measures of problem behaviors, time in sports (Wave I) was negatively associated with internalizing behaviors (Wave II). However, there was not a significant relation between time in sports and externalizing behavior. In addition to analyzing the relation between previous time in sports and subsequent problem behaviors, previous problem behaviors were used to predict subsequent time spent in sport. Results showed that previous internalizing behavior (Wave I) was negatively associated with time in sports (Wave II), but only for females. Externalizing behavior was not related to subsequent time spent in sport.
\end{abstract}

\section{Introduction}

Participation in a variety of organized out-of-school activity contexts is a common occurrence for many young people (Larson, Hansen, \& Moneta, 2006; Mahoney, Larson, Eccles, 2005). While the choice of activities may vary among youth, evidence suggests that the greatest frequency of participation occurs in organized sports (Feldman, \& Matjasko, 2007; Larson, et al., 2006). In many cases, sports are often touted as contexts to promote positive developmental outcomes in youth (Danish, Forneris, \& Wallace, 2005; Fraser-Thomas, Cote, \& Deakin, 2005; Hedstrom, \& Gould, 2004; Larson, 2000; Perks, 2007; Rosewater, 2009). However, there is also evidence that suggests athletic participation can be associated with negative behaviors (Eccles, \& Barber, 1999; Endressen, \& Olweus, 2005; Klein, \& Sorenson, 2002; Young, 2002). As the literature contains mixed findings about the direction and magnitude of effects associated with sports participation, the question as to whether sport participation promotes or inhibits problem behaviors remains. This study helps describe the 
direction of association between youth sport, as defined by organized participation in sports leagues, and any associated problem behavior.

Within the literature, the assessment of problem behavior has been of particular interest in relation to sports participation (Endressen, \& Olweus, 2005; Gardner, Roth, \& Brooks-Gunn, 2009; Miller, Melnick, Barnes, Sabo, \& Farrell, 2007; Rutten, et al., 2007; Smith, Smoll, \& Christensen, 1996). However, many of these studies utilize a cross-sectional design to assess the relation between sports participation and problem behavior for those youth already involved in sport (Endressen, \& Olweus, 2005; Perk, 2007; Rutten, et al., 2007). While these studies are useful for describing potential associations between participation and problem behaviors, they are limited in their ability to make any claims of cause and effect. The question of whether the youths' behavior is reflective of behavior they had prior to participation remains. To better understand the direction of association between sport participation and behavior, it is important to consider both effects of sports participation on participant behavior, while also considering the factors that influence youth participation.

\section{Sports Participation and Problem Behavior}

When studying sport participation and associated problem behaviors, there are two viewpoints one can take. One is to assess the associated effects of sport participation and behaviors that occur within the participant (i.e., depression, anxiety, sadness, etc.), which are called internalizing behaviors. The other perspective is to assess the relation between sport participation and behaviors the participant does toward others (i.e., aggression, arguing, disobediences, etc.), which are called externalizing behaviors.

As it relates to internalizing behaviors specifically, evidence suggests sport participation is associated with decreased depression (Dishman, et al.,2006; Gore, Farrell, \& Gordon, 2001), anxiety (Binsinger, Laure, \& Ambard, 2006), shyness (Findlay, \& Coplan, 2008; McHale, Vinden, Bush, Richer, Shaw, \& Smith, 2005), and other internalizing behaviors (Donaldson, \& Ronan, 2006). However, Gore, et al. (2001) found sport involvement was only associated with decreased depressive symptoms in females, not males, which may suggest differential effects between genders.

As it relates to externalizing behaviors, results are mixed across studies. There is some evidence to suggest sports participation is associated with decreased delinquency (Hastad, Segrave, Pangrazi, \& Petersen, 1984) while there is also evidence that suggests sport participation is associated with increased aggressive behaviors (Endressen, \& Olweus, 2005). Additionally, Donalson and Ronan (2006) suggest that sports participation is associated with lower externalizing behavior scores among adolescents, while results from a recent study (Gardner, et al., 2009) suggest male sport participation is associated with increased odds of nonviolent delinquent behavior when compared to non-athletic organized activity participants. In a crosssectional study of social adjustment and sport-involvement among adolescents, McHale and colleagues (2005) found sport-involved females were more aggressive than non-involved peers, whereas the opposite was true for males. Higher aggression ratings were associated with noninvolvement in sports, in males. Again, these results suggest that sports participation may have differential effects based on gender.

Fewer studies have assessed the relations between sport participation and internalizing and externalizing behaviors within the same study (Bohnert, \& Garber, 2007). In a longitudinal study of 198 adolescents, Bohnert and Garber (2007) found organized sports were marginally 
associated with lower levels of internalizing behavior. In the same study, however, greater involvement was associated with decreased externalizing behavior. Both results held when controlling for baseline measures of the behaviors. Additionally, results from this study showed increased baseline measures of both, internalizing and externalizing behavior were associated with decreased involvement in sports.

\section{Factors Influencing Participation}

Youth participate in organized sports for a variety of reasons. Typically, studies examining sport participation have utilized various theories of motivation to assess the youth's perception of his or her sport experiences. Through this work, a variety of intrinsic, or internal, motivators have been described. Some of the motivating factors that positively influence prolonged engagement in sport are related to the individual and include desires to have fun, to be with friends, and/or to demonstrate physical competence (Coakley, \& White, 1992; Weiss, Smith, \& Theeboom, 1996/2007; Weiss, \& Williams, 2004). Furthermore, Fraser-Thomas and Cote (2009) suggest that meaningful relationships with adults, a sense of community, and opportunities to explore positive life experiences also influence prolonged engagement.

An additional individual factor considered to influence selection into sport is the participant's previous behaviors (Endressen, \& Olweus, 2005; Marsh, \& Kleitman, 2003; McHale, et al., 2005). In a cross-sectional study of "power sports" (combative sports, wrestling, and weight lifting), Endressen and Olweus (2005) suggest that increased violent behavior and antisocial behavior by the athletes in these sports may reflect personality traits that predispose them towards participation. Additionally, McHale and colleagues (2005) suggest decreased problem behavior may be a pragmatic response by student athletes to remain eligible to play and not necessarily a reflection on the sport itself. Controlling for the participant's previous behaviors is needed to understand the influence of sport participation on future behaviors.

Other factors that influence sport participation are related to the environment in which the youth resides and include family characteristics (Azar, Naughton, \& Joseph, 2009; Barnett, \& Weber, 2008; Brustad, \& Partridge, 2002; Quarmby, \& Dagkas, 2010; Ullrich-French, \& Smith, 2009) and socioeconomic and neighborhood level characteristics (Kamphius, et al., 2007). Interviewing youth (ages 11-14 years old), Quarmby and Dagkas (2010) found family structure plays a vital role in predicting youth's dispositions toward physical activity and sport participation. In particular, youth from single parent families are less likely to be involved than youth from intact couple families. Additionally, Kamphius and colleagues (2007) found perceptions of neighborhood safety and family background (income and parental education) to significantly influence youth participation in organized sports. As Feldman and Matjasko (2005) state, "Extracurricular activities are not isolated from other developmental contexts; rather, they are embedded in schools and communities and influenced by families and peers" (p. 160). With the variety of selection factors influencing sport participation, it is important to control for them when assessing any associated relations between sport participation and behavior.

\section{Methodological Design of Previous Research}

Despite an accumulating body of research showing significant links between youth sport participation and problem behaviors, several important gaps in this literature limit what can be concluded about the directions of association. For example, many studies use a cross-sectional design (Donaldson, \& Ronan, 2006; Endressen, \& Olweus, 2005; Faulkner, et al., 2007; Hastad, et al., 1984; Harris, \& Eccles, 2005; Perks, 2007; Rutten, et al., 2007) making it difficult to 
make any causal inferences between sport participation and associated problem behavior. Without controlling for previous problem behaviors, the extent to which sports participation predicts behavior is not entirely clear. The use of a longitudinal design is preferred as it offers the ability to control for previous problem behaviors (Bohnert, \& Garber, 2007; Gardner, et al., 2009; Miller, et al., 2007). Furthermore, problem behaviors have most commonly been assessed using brief checklists or self-report items, rather than well-validated measures of symptoms (e.g., Behavior Problem Index). Therefore, the present study examined the relation between sport participation and adolescent behavior by using sound measures and controlling for previous behavior.

In addition to overall design of the studies, the operationalization of sports participation varies across studies. For example, some studies dichotomize (i.e. "yes" or "no") sports participation (Gardner, et al., 2009; Harris, \& Eccles, 2005; McHale, et al., 2005; Miller, et al., 2007), while others use ordinal survey ranges (i.e. "never participate" to "every day") to assess participation (Darling, 2005; Linver, et al., 2009). Still others (Mahoney, Harris, \& Eccles, 2006) use time diaries to assess activity participation. The dosage of sport participation may account for some of the variability in associations between sports participation and problem behavior, so it is important to include it in any analysis to this regard. Furthermore, many studies of sports participation utilize smaller, more localized samples of convenience, with few studies utilizing a nationally representative sample. The present study expands on this literature by examining the relation of time spent in sport (dosage) and subsequent problem behaviors using a nationally representative sample.

\section{Purpose of the Present Research}

The purpose of this study was to provide a longitudinal analysis of the associations between sport participation and internalizing and externalizing behavior. It was hypothesized that increased time spent in sport will be associated with decreased internalizing problem behaviors but increased externalizing problem behaviors. To account for the selection effect into sport, a secondary purpose of our study was to analyze the ability to predict sport participation using behavior measures. It was hypothesized that prior internalizing behavior will be associated with decreased time spent in sport, while prior externalizing behavior will be associated with increased time spent in sport. Also, an additional purpose of this study was to describe any gender differences in the relation between sport and problem behavior, so it was hypothesized that time spent in sport will be associated with increased externalizing behavior in males, but not in females. Results for internalizing behavior will be consistent for males and females. It was also hypothesized that any decrease in time spent in sport due to prior internalizing behavior will be particularly salient in females.

\section{Sample}

\section{Method}

The Panel Study of Income Dynamics (PSID) is a longitudinal survey of a representative sample of U.S. men, women, and children and the subsequent families they make up. Data were collected every year between 1968 and 1997, after which biennial data collection occurred. Between February 1996 and June 1998, the first wave of the PSID Child Development Supplement (Wave I) was initiated, which collected data on parents and their children from birth to age 12 (Hofferth, Davis-Kean, Davis, \& Finkelstein, 1997). The CDS was added to the PSID to offer a nationally representative sample of children and families to be used in research on the relation between parental and community resources on child development. 
The initial sample of the CDS (Wave I) consisted of 2,394 families (3,563 children ages 0-12) representing $88 \%$ of all families from the 1997 PSID assessment. The second wave of CDS (Wave II) data was collected in 2002-03 and included 2,019 families (2,907 children and adolescents ages 5-18) whose families remained active in the PSID study. Overall, $91 \%$ of families who took part in Wave I (1997) continued to participate in Wave II (2002-2003). The reduction in sample size from Wave I to Wave II is the result of either attrition due to nonparticipation ( $N=364$ children) or because some families left the PSID study before 2001 or were not part of the PSID core sample in 1968 ( $N=292$ children).

Data for both waves of the CDS included time diaries and primary caregiver interviews. Two time diaries (one weekday and one weekend) were collected per child. Trained interviewers collected the child's time diaries and then created codes for the child's respective activities. The PSID has been used previously in sport-related research (Harris, \& Eccles, 2005; Linver, et al., 2009).

Because many sports organizations require youth to be at least six years of age to participate, the current study focused on adolescents 11-19 years of age during Wave II ( $n=1692, M=$ 14.85 years, $S D=2.24$ ). Any younger, and the youth may not have been eligible to participate in sports at Wave I, which would limit the interpretation of the longitudinal design. However, data were used from both the Wave I and Wave II. Demographic characteristics of the participants included: age (Wave II), gender, and ethnicity. Data from all waves of the CDS were weighted to be representative of the national adolescent population and all analyses performed were computed using this sample weight. The sample was $49 \%$ males and $63 \%$ European American, 17\% African American, 13\% Hispanic, and 7\% of other ethnic origin. As all analyses used in this study were based on a weighted sample, results are generalizable to the national population. All analyses were approved by the university institutional review board (IRB).

\section{Measures}

Time in Sports. Participation in organized sports was coded from time diaries in both Wave I and Wave II. Only time diary codes specific to "lessons," "practices," "matches," and "games," related to sports activities, were considered for analysis. Time diary measures were recoded from number of seconds the youth participated in a given sport activity to number of minutes per day. Time diary entries had to be greater than 15 minutes to be considered for analysis, and all time diary entries under 15 minutes were considered zero. To create a measure of time in sports, the total number of minutes spent in sport-related activity (based on CDS codes) was added together in both time diary 1 (weekday) and 2 (weekend). The total minutes from weekday and weekend entries were averaged to estimate mean number of minutes per day.

Behavior problems. The Behavior Problem Index (BPI) was developed by Peterson and Zill (1986) and is an adaptation of the Achenbach Behavior Problems Checklist (Achenbach, \& Edelbrock, 1983). It is a 28-item scale that measures externalizing and internalizing behavior problems. The externalizing behavior subscale of the BPI consists of 15-items (Chronbach's alpha $=.86$ ) and includes questions like: "breaks things on purpose or deliberately destroys (his/her) own or another's things," "does not seem to feel sorry after (he/she) misbehaves," and "has a very strong temper and loses it easily." The internalizing behavior subscale consists of 13-items (Chronbach's alpha = .81) and includes questions like: "cries too much," "is too dependent on others," and "is withdrawn, does not get involved with others." Parents were 
asked whether each behavior is often true, sometimes true, or not true of their child. A higher score on each of the subscales represents greater problem behavior.

Family characteristics. Family characteristics were obtained from PSID core data and included: family income (rescaled by $\$ 10,000$ ), highest level of educational attainment of the family head (top-coded at 17 years), and whether the family had one or two parents living together. Family income was top-coded at $\$ 200,000$ (Linver, et al., 2009). Each increment of educational attainment of the family education represents an additional year of school.

Neighborhood characteristics. To control for neighborhood influence on sport participation a neighborhood quality scale was developed (Mahoney, 2010). The scale was created using survey responses from two questions on the parent survey of Wave II. The two questions were: "How safe is your neighborhood to walk around after dark?" (range 1-4, "4" = "extremely dangerous") and "How would you rate your neighborhood as a place to raise children?" (range of $1-5, " 5 "=$ "poor"). Both responses were standardized to a mean of zero and added together to create the neighborhood scale (Mahoney, 2010), which had a Chronbach's alpha of .62, which is acceptable consistency for a 2-item scale.

\section{Analytic Strategy}

The analytical strategy involved four steps. First, a cross-lagged model was developed (Figure 1) to describe whether sport participation predicted behavior indicators, (i.e., externalizing behaviors) or if behavior indicators predicted sport participation. Next, missing data were imputed using Stata's ICE program (Royston, 2004; UCLA). A series of ten imputations were used to complete the total number of cases.

Figure 1

Conceptual diagram of longitudinal relations between sports participation and behavior

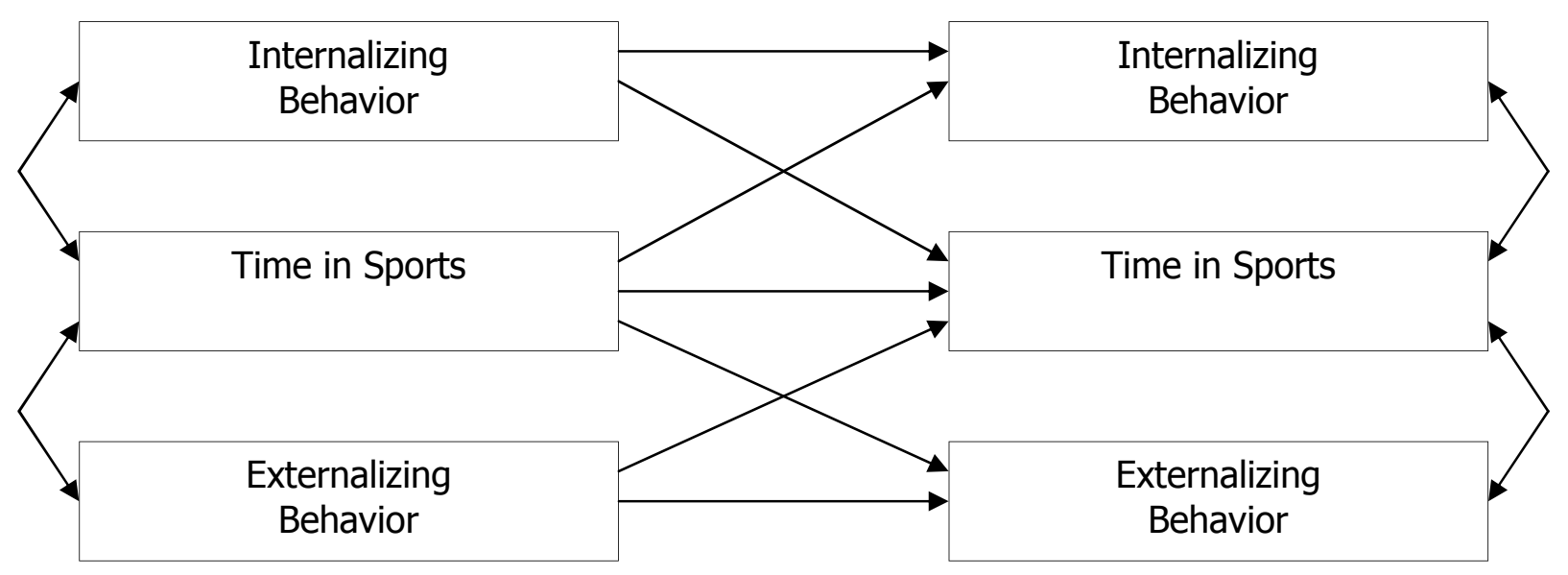

Following the imputations, behavior outcomes were examined using a series of Ordinary Least Squares (OLS) regressions. In the model, time spent in sport (Wave I) was used as the key independent variable predicting either internalizing or externalizing behavior scores (Wave II). 
However, to control for the individual factors influencing selection into sports, the baseline (Wave I) measure of the behavior problem score of interest, age, gender, and ethnicity were added to the model. Additionally, family (income, head education, and whether single parent household) and neighborhood characteristics were added to the model. An interaction term between time spent in sport in Waves I and II was added to account for prolonged engagement in sport. This model was used to describe the relation between prior sport participation and future problem behaviors.

To capture the predictive influence of problem behaviors on future participation in sports, the last stage of analysis used baseline behavior indicators (Wave I) to predict time spent in sport (Wave II) using OLS regressions. The relevant baseline behavior problem scores were used as the key independent variables. The individual, family, and neighborhood controls as described previously were also added. To control for previous time spent in sport, the Wave I measure was also included.

To test for differences across gender, the total sample was separated into gender-based subsamples and all models were applied to each subsample.

\section{Results}

Descriptive characteristics of the sample are provided in Table 1. Mean sport participation from the Wave I was 6.71 minutes ( $S D=12.81$ mins), while the mean for Wave II was 6.61 minutes ( $S D=14.21$ minutes). The mean for the baseline (Wave I) externalizing behavior scores was $5.48(S D=3.86)$, while the mean for the baseline internalizing scores was $2.70(S D=2.82)$.

\section{Table 1}

\begin{tabular}{|c|c|c|c|c|}
\hline \multicolumn{5}{|c|}{ Means, Standard Deviations and Ranges for all Variables $N=1692$} \\
\hline Variable & M & SD & Range & $\%$ \\
\hline Age (years) & 14.85 & 2.24 & $11-19$ & \\
\hline Males $^{1}$ & & & $0-1$ & 49 \\
\hline White $^{2}$ & & & $0-1$ & 63 \\
\hline Black & & & $0-1$ & 17 \\
\hline Hispanic & & & $0-1$ & 13 \\
\hline Other & & & $0-1$ & 7 \\
\hline Family income $(\$ 10,000)$ & 7.61 & 9.90 & $-9.9-205.2$ & \\
\hline Head education & 12.73 & 2.75 & $0-17$ & \\
\hline Single-parent family ${ }^{3}$ & & & $0-1$ & 29 \\
\hline Neighborhood Scale & -.10 & 1.67 & $-2.51-5.33$ & \\
\hline Broad Reading Score ${ }^{4}$ & 104.2 & 17.63 & $42-186$ & \\
\hline Applied Problem Score ${ }^{4}$ & 106.7 & 17.76 & $28-159$ & \\
\hline Time in Sport Wave $\mathrm{I}^{5}$ & 6.71 & 12.81 & $0-97.73$ & \\
\hline Time in Sport Wave II $^{5}$ & 6.61 & 14.21 & $0-147.67$ & \\
\hline BPI - Internalizing Wave I & 2.70 & 2.82 & $0-13$ & \\
\hline BPI - Internalizing Wave II & 3.19 & 3.23 & & \\
\hline BPI - Externalizing Wave I & 5.48 & 3.86 & $0-15$ & \\
\hline BPI - Externalizing Wave II & 5.65 & 4.27 & & \\
\hline $\begin{array}{l}\text { Females are reference group. } \\
\text { eference group. }{ }^{4} \text { Woodcock-Jo } \\
\text { day. }\end{array}$ & $\begin{array}{l}\text { nicity is } \\
\text { essment. }\end{array}$ & ence gr & o. ${ }^{3}$ Two-pa & $\begin{array}{l}s \text { are } \\
\text { minut }\end{array}$ \\
\hline
\end{tabular}




\section{Associated impact of time in sport on internalizing behavior}

Table 2 contains the results from OLS regressions predicting internalizing behaviors. As indicated, Wave I sport participation has a significant negative relation $(\beta=-.029, p<.01)$ to internalizing problem behavior at Wave II. Moreover, this relation holds when the baseline measure for internalizing and externalizing behaviors and the individual, family, and neighborhood measures were used as controls. The interaction between Wave I and Wave II sport participation was not a significant predictor of Wave II internalizing behavior. When applied to the gender-based subsamples, there was no difference between males and females. Results from both gender subsamples mirrored those of the total sample.

\section{Associated impact of time in sport on externalizing behavior}

Table 2 also contains the results from OLS regressions predicting externalizing behaviors. As indicated, Wave I sport participation was not a significantly related $(\beta=-.010, p>.05)$ to externalizing problem behavior at Wave II. Moreover, this relation holds when the baseline measure for internalizing and externalizing behaviors and the individual, family, and neighborhood measures were used as controls. As with internalizing behavior, the interaction between Wave I and Wave II sport participation was not a significant predictor of Wave II internalizing behavior. Additionally, results from both gender subsamples mirrored those of the total sample.

Table 2

Regression Coefficients for Predicting Problem Behavior Scores

\begin{tabular}{|c|c|c|}
\hline \multicolumn{3}{|c|}{ Internalizing Behavior Wave II } \\
\hline Ind. Variable & $\beta$ & $95 \% \mathrm{CI}$ \\
\hline Time in Sport Wave I & $-.029^{* *}$ & {$[-.048,-.011]$} \\
\hline $\begin{array}{l}\text { Internalizing Behavior } \\
\text { Wave I }\end{array}$ & $.407^{* * *}$ & {$[.307, .506]$} \\
\hline $\begin{array}{l}\text { Externalizing Behavior } \\
\text { Wave I }\end{array}$ & $.164^{* * *}$ & {$[.099, .229]$} \\
\hline Controls & yes & \\
\hline Constant & $\left.3.478\right|^{* *}$ & {$[.867,4.32]$} \\
\hline \multicolumn{3}{|c|}{ Externalizing Behavior Wave II } \\
\hline Ind. Variable & $\beta$ & $95 \% \mathrm{CI}$ \\
\hline Time in Sport Wave I & -.010 & {$[-.032, .012]$} \\
\hline $\begin{array}{l}\text { Externalizing Behavior } \\
\text { Wave I }\end{array}$ & $.606^{* * *}$ & {$[.527, .684]$} \\
\hline $\begin{array}{l}\text { Internalizing Behavior } \\
\text { Wave I }\end{array}$ & -.044 & {$[-.161, .073]$} \\
\hline Controls & yes & \\
\hline Constant & $2.670^{*}$ & {$[.681,4.65]$} \\
\hline \multicolumn{3}{|c|}{$\begin{array}{l}\text { Notes: Additional controls include individual (age, gender, and ethnicity), } \\
\text { family (family income, whether single-parent family, and head education), } \\
\text { and neighborhood measures. } \\
* p<.05 .{ }^{* *} p<.01 . * * * p<.001 \text {. }\end{array}$} \\
\hline
\end{tabular}




\section{Associated impact of problem behavior on sport participation}

Table 3 displays the results of OLS regression equations predicting whether Wave I behavior measures were related to sport participation at Wave II. Baseline internalizing behaviors had a significant negative relation $(\beta=-.516, p<.05)$ to Wave II time spent in sports. Baseline externalizing behaviors were not significantly related to Wave II time spent in sport. These results remain consistent with the addition of individual, family, and neighborhood controls. Previous time spent in sport (Wave I) had a positive significant relation $(\beta=.079, p<.05)$ to subsequent (Wave II) time spent in sport.

When applied to the female subsample (Table 3, Females), baseline internalizing behavior scores have a significant negative $(\beta=-.627, p<.05)$ relation to time spent in sport participation at Wave II. This relation remains consistent with the addition of all the controls to the model. Baseline externalizing behavior was not related to time spent in sport in Wave II. In males, neither internalizing nor externalizing behavior scores were predictive of time spent in sport.

Table 3

Regression Coefficients for Predicting Time in Sport

\begin{tabular}{|c|c|c|c|c|c|c|}
\hline & \multicolumn{6}{|c|}{ Time Spent in Sport Wave II } \\
\hline & \multicolumn{2}{|c|}{ Full Sample } & \multicolumn{2}{|c|}{ Males } & \multicolumn{2}{|c|}{ Females } \\
\hline Ind. Variable & $\beta$ & $95 \% \mathrm{CI}$ & $\beta$ & $95 \% \mathrm{CI}$ & $\beta$ & $95 \% \mathrm{CI}$ \\
\hline $\begin{array}{l}\text { Internalizing } \\
\text { Baseline Wave I }\end{array}$ & $-.516^{*}$ & {$[-.940,-.093]$} & -.399 & {$[-.996, .199]$} & $-.627^{*}$ & {$[-1.23,-.025]$} \\
\hline $\begin{array}{l}\text { Externalizing } \\
\text { Baseline Wave I }\end{array}$ & .162 & {$[-.142, .467]$} & .144 & {$[-.302, .590]$} & .203 & {$[-.211, .617]$} \\
\hline $\begin{array}{l}\text { Time in Sport } \\
\text { Wave I }\end{array}$ & $.079^{*}$ & $\begin{array}{l}.002, \\
.155] \\
\end{array}$ & .064 & {$[-.027, .155]$} & .121 & {$[-.029, .270]$} \\
\hline Controls & yes & & yes & & yes & \\
\hline Constant & -.055 & {$[-7.64,7.53]$} & -.745 & {$[-12.4,10.9]$} & 1.45 & {$[-9.20,12.1]$} \\
\hline
\end{tabular}

\section{Discussion}

The purpose of this study was to help clarify the relation between sport participation and problem behaviors using a longitudinal design. The central question of interest was whether sports participation is protective towards the development of problem behaviors in adolescence. Additionally, as uncontrolled for selection factors make results from existing literature difficult to interpret, the design of the current study offered the opportunity to test the predictive abilities of prior behavior problems.

The following conclusions are supported by the findings from this study. First, greater time spent in sport in childhood was associated with decreased internalizing behavior in adolescence. Second, prior sport participation was not significantly associated with externalizing behavior. Third, previous internalizing behavior was negatively associated with sport participation, but only for females. Fourth, previous externalizing behavior was not significantly predictive of subsequent time spent in sport. 
The findings from this study were consistent with other research demonstrating the benefits of sports participation (Harris, \& Eccles, 2005; Rutten, et al., 2007; Zarrett, et al., 2009). When predicting internalizing behavior, previous time spent in sports was negatively associated with decreased internalizing behavior scores, even when controlling for prior internalizing behavior, as well as individual, family, and neighborhood measures. These results suggest that early sport participation may protect against development of depression, anxiety, and/or other internalizing behaviors.

However, the results from this study challenge existing literature suggesting a protective relation between sport participation and externalizing behavior (Donaldson, \& Ronan, 2006). While there was a significant negative relation between prior time spent in sport and externalizing behavior for males, this result was only observed when sport was used as the sole predictor or when previous externalizing behavior scores were included in the model. When additional controls were added to the model, the association between sport participation and externalizing behavior was no longer statistically significant. These results suggest that family and neighborhood characteristics must be accounted for when testing the relation between sport and problem behavior.

Of interest, when testing for the ability to predict sport participation from baseline behavior scores, internalizing behavior was the only significant predictor of time spent in sport. The relation was negative, which suggests youth with high internalizing behavior are less likely to be involved in sports than youth with lower internalizing behavior. However, this result was only significant for the female subsample, so females may be of particular interest for future studies regarding selection factors into sport-related activities. Unfortunately, as the results from the current study suggest, these youth (females) are the ones that could benefit from sport participation. So, one practical application of the results would be to develop intervention programs designed to increase sport participation among females with higher internalizing behavior. Involvement in sports during childhood may be more beneficial than waiting to get youth involved in adolescence.

\section{Limitations}

One limitation of the current study is the extended time (five years) that exists between the Wave I and Wave II data. Within the two time points, it is unknown what activities the youth participated in, so there is limited information regarding the extended dosage of sports participation. Another limitation to the study is the generalization of sports participation. Due to limitations in the data, the current study was unable to study any differences between types of sports. In the Wave I time diaries; sport participation was categorized as either "Team" or "Individual," which limited comparisons between specific sports. As sport participation could not be separated into individual types of sports, a general measure of total "time in sports" was used for the analyses in the current study. While sport-related activity codes of the Wave II did reflect separate sport types, these were combined to mirror the measures derived from the Wave I. Certain sports may have differential effects on the development of problem behavior than others. Another limitation to the study is the lack of data regarding the quality of sports programming within the time diaries.

\section{Future Research Implications}

While the current study extends the literature on youth sports and the development of behavior problems, the findings point to several avenues for further research. For one, the results should 
be tested on specific types of sports to determine if certain sports are more protective than others on the development of problem behavior (Endressen, \& Olweus, 2005). Additionally, the absence of problem behavior does not necessarily equate to positive behavior, so the design of future studies should include measures of positive development across time points (Lerner, Almerigi, Theokas, Lerner, 2005; Zarrett, et al., 2009). Another extension of the study would be to replicate its design over three time points of data. Two time points offer the opportunity to describe a trend, but they are limited in the ability to ascribe causality.

Additionally, due to limitations within the data, all types of sports were lumped together as "sports." Individual types of sports may have differences in associated effect on problem behavior, so it will be important to examine the effect of individual sports on problem behavior in the future. Also, recent studies suggest sport participation may have greater influence on youth adjustment when coupled with other organized activities (Linver, et al., 2009; Zarrett, et al., 2009), so future studies should address the sport-related context as it relates to other ways youth spend their out-of-school time (Mahoney, Lord, Carryl, 2005).

\section{Acknowledgements:}

This study was supported by a grant from the National Institute of Child Health and Human Development (R03HD055318). The authors would like to thank George Farkas, Greg Duncan, and Anne Marie Conley for advice regarding analytic strategy.

\section{References}

Achenbach, T.M., \& Edelbrock, C.S. (1983). Manual for the child behavior checklist. Burlington: Department of Psychiatry, University of Vermont.

Azar, D., Naughton, G.A., \& Joseph, C.W. (2009). Physical activity and social connectedness in single-parent familie. Leisure Studies, 28, 349-358.

Barnett, L.A., \& Weber, J.J. (2008). Perceived benefits to children from participating in different types of recreational activities. Journal of Park and Recreation Administration, 26, 1-20.

Binsinger, C., Laure, P., \& Ambard, M-F. (2006). Regular extracurricular sports practice does not prevent moderate or severe variations in self-esteem or trait anxiety in early adolescents.

Journal of Sports Science and Medicine, 5, 123-129.

Bohnert, A.M., \& Garber, J. (2007). Prospective relations between organized activity participation and psychopathology during adolescence. Journal of Abnormal Child Psychology, 35, 1021-1033.

Brustad, R.J., \& Partridge, J.A. (2002). Parental and peer influence on children's psychosocial development through sport. In F.L. Smoll, \& R.E. Smith (Eds.), Children and youth in sport: $A$ biopsychosocial perspective (2nd ed.) (pp. 187-210). Dubuque, IA: Kendall/Hunt.

Coakley, J., \& White, A. (1992). Making decisions: Gender and sport participation among British adolescents. Sociology of Sport Journal, 9, 20-35.

Danish, S.J., Forneris, T., \& Wallace, I. (2005). Sport-based life skills programming in the schools. Journal of Applied School Psychology, 21, 41-62. 
Darling, N. (2005). Participation in extracurricular activities and adolescent adjustment: crosssectional and longitudinal findings. Journal of Youth and Adolescence, 34, 493-505.

Dishman, R.K., Hales, D.P., Pfeiffer, K.A., Felton, G., Saunders, R., Ward, D.S., et al. (2006). Physical self-concept and self-esteem mediate cross-sectional relations of physical activity and sport participation with depression symptoms among adolescent girls. Health Psychology, 25, 396-407.

Donaldson, S.J., \& Ronan, K.H. (2006). The effects of sports participation on young adolescents' emotional well-being. Adolescence, 41, 369-389.

Eccles. J.S., \& Barber, B.L. (1999). Student council, volunteering, basketball, or marching band: What kind of extracurricular involvement matters? Journal of Adolescent Research, 14, 10-43.

Endressen, I.M., \& Olweus, D. (2005). Participation in power sports and antisocial involvement in preadolescent and adolescent boys. Journal of Child Psychology and Psychiatry, 46, 468-478.

Faulkner, G.E.J., Adlaf, E.M., Irving, H.M., Allison, K.R., Dwyer, J.J. M., \& Goodman, J. (2007). The relationship between vigorous physical activity and juvenile delinquency: A mediating role for self-esteem? Journal of Behavioral Medicine, 30, 155-163.

Feldman, A.F., \& Matjasko, J.L. (2005). The role of school-based extracurricular activities in adolescent development: A comprehensive review and future directions. Review of Educational Research, 75, 159-210.

Feldman, A.F., \& Matjasko, J.L. (2007). Profiles and portfolios of adolescent school-based extracurricular activity participation. Journal of Adolescence, 30, 313-332.

Findlay, L.C., \& Coplan, R.J. (2008). Come out and play: Shyness in childhood and the benefits of organized sports participation. Canadian Journal of Behavioural Science, 40, 153-161.

Fraser-Thomas, J.L., \& Cote, J. (2009). Understanding adolescents' positive and negative developmental experiences in sport. The Sport Psychologist, 23, 3-23.

Fraser-Thomas, J.L., Cote, J., \& Deakin, J. (2005). Youth sport programs: An avenue to foster positive youth development. Physical Education \& Sport Pedagogy, 10, 19-40.

Gardner, M., Roth, J., \& Brooks-Gunn, J. (2009). Sports participation and juvenile delinquency: The role of the peer context among adolescent boys and girls with varied histories of problem behavior. Developmental Psychology, 45, 341-353.

Gore, S., Farrell, F., \& Gordon, J. (2001). Sports involvement as protection against depressed mood. Journal of Research on Adolescence, 11, 119-130.

Harris, A.L., \& Eccles, J.S. (2005). Relation between sport/exercise participation and other indicators of healthy adolescent development. CDS-II Early Results Workshop, MI. Retrieved from http://psidonline.isr.umich.edu. 
Hastad, D.N., Segrave, J.O., Pangrazi, R., \& Peterson, G. (1984). Youth sport participation and deviant behavior. Sociology of Sport Journal, 1, 366-373.

Hedstrom, R., \& Gould, D. (2004). Research in youth sports: Critical issues status. Retrieved June 1, 2010, from Michigan State University Institute for the Study of Youth Sports Web page: http://www.educ.msu.edu/ysi/project/CriticalIssuesYouthSports.pdf

Hofferth, S.L., Davis-Kean, P., Davis, J., \& Finkelstein, J. (1997). The child development supplement to the panel study of income dynamics: 1997 user guide. Available from http://isr.umich.edu/src/child-development/usergd.html

Kamphuis, C.B.M., van Lenthe, F.J., Giskes, K., Huisman, M., Brug, J., \& Mackenbach, J.P. (2007). Socioeconomic status, environmental and individual factors, and sports participation. Medicine and Science in Sports \& Exercise, 40, 71-81.

Klein, M.W., \& Sorenson, S.B. (2002). Contrasting perspectives on youthful sports violence. In Gatz, M., Messner, M.A., \& Ball-Rokeach, S.J. (Eds.). Paradoxes of Youth and Sport (pp. 197206). Albany, NY: State University of New York Press.

Larson, R.W. (2000). Toward a psychology of positive youth development. American Psychologist, 55, 170-183.

Larson, R.W., Hansen, D.H., \& Moneta, G. (2006). Differing profiles of developmental experiences across types of organized activities. Developmental Psychology, 42, 849-863.

Lerner, R.M., Almerigi, J.B., Theokas, C., Lerner, J.V. (2005). Positive youth development: A view of the issues. Journal of Early Adolescence, 25, 10-16.

Linver, M.R., Roth, J.L., \& Brooks-Gunn, J. (2009). Patterns of adolescents' participation in organized activities: Are sports best when combined with other activities? Developmental Psychology, 45, 354-367.

Mahoney, J.L. (2010). Adolescent summer care arrangements and the development of obesity. Journal of Adolescence. Available online September 21, 2010.

Mahoney, J.L., Harris, A.L., \& Eccles, J.S. (2006). Organized activity participation, positive youth development, and the over-scheduling hypothesis. SRCD Social Policy Report, 20, 1-31.

Mahoney, J.L., Larson, R.W., \& Eccles, J.S. (Eds.). (2005). Organized activities as contexts of development: Extracurricular activities, after-school, and community programs. Mahwah, NJ: Erlbaum.

Mahoney, J.L., Lord, H., \& Carryl, E. (2005). An ecological analysis of after-school program participation and the development of academic performance and motivational attributes for disadvantaged children. Child Development, 76, 811-825.

Marsh, H.W., \& Kleitman, S. (2003). School athletic participation: Mostly gain with little pain. Journal of Sport and Exercise Psychology, 25, 205-228. 
McHale, J.P., Vinden, P.G., Bush, L., Richer, D., Shaw, D., \& Smith, B. (2005). Patterns of personal and social adjustment among sport-involved and noninvolved urban middle-school children. Sociology of Sport Journal, 22, 119-136.

Miller, K., Melnick, M.J., Barnes, G.M., Savo, D., \& Farrell, M.P. (2007). Athletic involvement and adolescent delinquency. Journal of Youth and Adolescence, 36, 711-723.

Perks, T. (2007). Does sport foster social capital? The contribution of sport to a lifestyle of community participation. Sociology of Sport Journal, 24, 378-401.

Peterson, J.L., \& Zill, N. (1986). Marital disruption, parent-child relationships, and behavior problems in children. Journal of Marriage and the Family, 48, 295-307.

Quarmby, T., \& Dagkas, S. (2010). Children's engagement in leisure time physical activity: Exploring family structure as a determinant. Leisure Studies, 29, 53-66.

Rosewater, A. (2009). The 2009 Team-Up for Youth Monograph Series, Learning to play and playing to learn: Organized sports and educational outcomes. Oakland, CA: Team-Up for Youth.

Royston, P. (2004). Multiple imputation of missing values. Stata Journal, 4, 227-241.

Rutten, E.A., Stams, G.J.J.M., Biesta, G.J.J., Schuengel, C., Dirks, E., \& Hoeksma, J.B. (2007). The contribution of organized youth sport to antisocial and prosocial behavior in adolescent athletes. Journal of Youth and Adolescence, 36, 255-264.

Smith R.E., \& Smoll, F.L., \& Christensen, D.S. (1996). Behavioral assessment and interventions in youth sports. Behavior Modification, 20, 3-44.

UCLA: Academic Technology Services, Statistical Consulting Group. Multiple imputation using ICE. from http://www.ats.ucla.edu/stat/Stata/library/ice.htm (accessed August 11, 2009).

Ullrich-French, S., \& Smith, A.L. (2009). Social and motivational predictors of continued sport participation. Psychology of Sport and Exercise, 10, 87-95.

Weiss, M.R., Smith, A.L., \& Theeboom, M. (2007). "That's what friends are for:" Children's and teenagers' perceptions of peer relationships in the sport domain. In D. Smith \& M. Bar-Eli (Eds. ), Essential readings in sport and exercise psychology (pp. 439-453). Champaign, IL: Human Kinetics. (Reprinted from "That's what friends are for:" Children's and teenagers' perceptions of peer relationships in the sport domain, by M.R. Weiss, A.L. Smith, \& M. Theeboom, 1996, Journal of Sport and Exercise Psychology, 18, 347-379.

Weiss, M.R., \& Williams, L. (2004). The why of youth sport involvement: A developmental perspective on motivational processes. In M.R. Weiss (Ed.). Developmental sport and exercise psychology: A lifespan perspective (pp. 223-268). Morgantown, WV: Fitness Information Technology, Inc.

Young, K. (2002). From "sports violence" to "sports crime": Aspects of violence, law, and gender in the sports process. In Gatz, M., Messner, M.A., \& Ball-Rokeach, S.J. (Eds.). Paradoxes of Youth and Sport (pp. 207-224). Albany, NY: State University of New York Press. 
Zarrett, N., Fay, K., Li, Y., Carrano, J., Phelps, E., \& Lerner, R.M. (2009). More than child's play: variable- and pattern-centered approaches for examining effects of sports participation on youth development. Developmental Psychology, 45, 368-382.

(C) Copyright of Journal of Youth Development Bridging Research and Practice. Content may not be copied or emailed to multiple sites or posted to a listserv without copyright holder's express written permission. However, users may print, download or email articles for individual use. 